\title{
The effect of mad honey on testosterone levels of male rats
}

\author{
Tatli $\mathrm{O}^{1}$, Karaca $\mathrm{Y}^{1}$, Turkmen $\mathrm{S}^{2}$, Gulgen $\mathrm{GS}^{3}$, Sahin $\mathrm{A}^{1}$, Eryigit $\mathrm{U}^{1}$, Fazli $\mathrm{O}^{4}$, Karaguzel E ${ }^{5}$, \\ Mentese $\mathrm{A}^{6}$, Orem $\mathrm{A}^{6}$, Cansu $\mathrm{A}^{7}$, Turedi $\mathrm{S}^{1}$, Gunduz $\mathrm{A}^{1}$ \\ Karadeniz Technical University, Faculty of Medicine, Department of Emergency Medicine, 61000, \\ Trabzon, Turkey.dr.ozgurtatli@gmail.com
}

\begin{abstract}
OBJECTIVE: We aimed to investigate the effect of mad honey on sexual performance.

BACKGROUND: In traditional medicine in Turkey, mad honey is used to improve appetite, to heighten mental alertness, to reduce joint pain, to eliminate gastrointestinal system pains and to increase sexual performance. METHODS: In this experimental animal study eighteen Sprague Dawley male rats were randomized into three groups, a control group, a normal honey group and a mad honey group. Rats in the treatment groups were given a daily dose of $80 \mathrm{mg} / \mathrm{kg}$ normal honey or mad honey throughout the 30-day study period. Total testosterone, free testosterone, FSH, LH, estradiol, and progesterone levels were subsequently investigated from blood sera on day 30.

RESULTS: Comparison of blood total testosterone levels among the groups revealed significantly higher levels in the mad honey group compared to the normal honey and control groups $(p=0.006, p=0.00)$. Free testosterone levels were also significantly higher in the mad honey group than in the normal honey and control groups $(p=0.023, p=0.01)$. No statistically significant differences were determined for other hormonal measurements. CONCLUSIONS: This study revealed a significant increase in both total and free testosterone levels in mad-honey group (Tab. 1, Fig. 2, Ref. 16). Text in PDF www.elis.sk.

KEY WORDS: mad honey, grayanotoxin, traditional medicine, sexual performance, testosterone.
\end{abstract}

\section{Introduction}

Traditional therapeutic techniques using natural products are increasing rapidly across the world. Mad honey is known due to intoxications encountered during its use as both a therapeutic product and as a normal foodstuff for hundreds of years. (1). The mechanism involved in the formation of mad honey largely involves the grayanotoxin (GTX) contained in the nectars of the plants Rhododendron ponticum and Rhododendron luteum being mixed into honey by bees (2).

Mad honey is used to improve appetite, to heighten mental alertness, to reduce joint pain, to eliminate gastrointestinal system pains and to increase sexual performance in traditional medicine in Turkey (3). The field where it is most widely used as a natural

${ }^{1}$ Karadeniz Technical University, Faculty of Medicine, Department of Emergency Medicine, Trabzon, Turkey, ${ }^{2}$ AcibademTaksim Hospital, Department of Emergency Medicine, Istanbul, Turkey, ${ }^{3}$ Celal Bayar University, School of VocationalHealth Service, Department of HistologyandEmbryology, Manisa, Turkey, ${ }^{4}$ Trabzon Fatih State Hospital, Department of Emergency Medicine, Trabzon, Turkey, ${ }^{5}$ Karadeniz Technical University, Faculty of Medicine, Department of Urology, Trabzon, Turkey, ${ }^{6}$ Karadeniz Technical University, Faculty of Medicine, Department of Biochemistry, Trabzon, Turkey, and ${ }^{7}$ Karadeniz Technical University, Faculty of Medicine, Department of Pediatric Neurology, Trabzon, Turkey

Address for correspondence: O. Tatli, Karadeniz Technical University, Faculty of Medicine, Department of Emergency Medicine, 61000, Trabzon, Turkey.

Phone: +90.04623771228, Fax: +90.04623250518 support product is to enhance sexual performance (4). Previous experimental studies have shown that GTX possesses analgesic, blood pressure lowering and heart rate lowering effects $(5,6)$

The great majority of affected individuals in published case series and studies of mad honey intoxications consist of adult males aged 40 or over $(3,4,8,9)$. The reason for this is probably the widespread belief that mad honey enhances male sexual performance (4). In this experimental study, the effect of mad honey used in traditional medicine on sexual performance was investigated.

\section{Material and methods}

\section{Study design}

Karadeniz Technical University Faculty of Medicine Animal Experiments Ethical Committee approval was obtained for this randomized, controlled experimental study (ethical approval no: 2013/5). All protocols were reviewed and approved by the institutional ethics committee for animal experimentation.

\section{Study setting and population}

Eighteen male Sprague Dawley rats obtained from the Karadeniz Technical University Faculty of Medicine Laboratory Animals Department and with a mean weight of 195-252 g were used in the study. The animals were housed under standard light/dark conditions (12-h light and 12-h dark) at constant temperature (21 + 1 ${ }^{\circ} \mathrm{C}$ ) and humidity (55 + $5 \%$ ) with unrestricted access to standard laboratory animal chow and water. 
Tab. 1a. Statistical analysis between groups in total hormone levels.

\begin{tabular}{|c|c|c|c|c|c|c|c|c|c|c|c|c|}
\hline & \multicolumn{3}{|c|}{ Total testosteronlevels } & \multicolumn{3}{|c|}{ Freetestosteron levels } & \multicolumn{3}{|c|}{ Estradiol levels } & \multicolumn{3}{|c|}{ Progesterone levels } \\
\hline & Control & $\begin{array}{l}\text { Normal } \\
\text { honey }\end{array}$ & $\begin{array}{c}\text { Mad } \\
\text { honey }\end{array}$ & Control & $\begin{array}{c}\text { Normal } \\
\text { honey }\end{array}$ & $\begin{array}{c}\text { Mad } \\
\text { honey }\end{array}$ & Control & $\begin{array}{c}\text { Normal } \\
\text { honey }\end{array}$ & $\begin{array}{c}\text { Mad } \\
\text { honey }\end{array}$ & Control & $\begin{array}{c}\text { Normal } \\
\text { honey }\end{array}$ & $\begin{array}{c}\text { Mad } \\
\text { honey }\end{array}$ \\
\hline $\begin{array}{l}\text { Mean } \\
\text { STD }\end{array}$ & $252.3 \pm 72.4$ & $327.6 \pm 61$ & $493.1 \pm 86.4$ & $0.6 \pm 0.2$ & $1.7 \pm 1.2$ & $6.2 \pm 3.4$ & $19.0 \pm 3.6$ & $22.7 \pm 5.2$ & $22.2 \pm 6.7$ & $1357 \pm 761.8$ & $852 \pm 208.3$ & $773 \pm 466.5$ \\
\hline Control & & & $0.000^{*}$ & & & $0.010^{*}$ & & & 0.3 & & & 0.1 \\
\hline $\begin{array}{l}\text { Normal } \\
\text { Honey }\end{array}$ & & & $0.006^{*}$ & & & $0.023^{*}$ & & & 0.8 & & & 0.7 \\
\hline
\end{tabular}

*INDEPENDENT SAMPLE TEST, statistically significant

Free and total testosterone levels in rats receiving mad honey were significantly higher than those in rats receiving normal honey $(\mathrm{p}=0.023$ and $\mathrm{p}=0.006$, respectively). No significant variation was determined in estradiol or progesterone levels ( $\mathrm{p}=0.8$ and $\mathrm{p}=0.7$, respectively). Free and total testosterone levels in rats receiving mad honey were also significantly higher than those in rats in the control group ( $p=0.010$ and $p=0.000$, respectively). No significant difference was determined between estradiol or progesterone levels $(\mathrm{p}=0.3, \mathrm{p}=0.1)$

Tab. 1b. Statistical analysis of the difference in hormone levles between the groups.

\begin{tabular}{|c|c|c|c|c|c|c|}
\hline & \multicolumn{3}{|c|}{ LH levels } & \multicolumn{3}{|c|}{ FSH levels } \\
\hline & Control & $\begin{array}{c}\text { Normal } \\
\text { honey }\end{array}$ & $\begin{array}{c}\text { Mad } \\
\text { honey }\end{array}$ & Control & $\begin{array}{c}\text { Normal } \\
\text { honey }\end{array}$ & $\begin{array}{c}\text { Mad } \\
\text { honey }\end{array}$ \\
\hline $\begin{array}{l}\text { Median } \\
\text { (Min-Max) }\end{array}$ & $\begin{array}{c}6.2^{\mathrm{a}} \\
(1.8-13.3)\end{array}$ & $\begin{array}{c}6.6^{\mathrm{a}} \\
(2.6-12.6)\end{array}$ & $\begin{array}{c}3.7^{\mathrm{a}} \\
(2.6-32)\end{array}$ & $\begin{array}{c}4.5^{\mathrm{b}} \\
(3.7-5.2)\end{array}$ & $\begin{array}{c}5^{\mathrm{b}} \\
\left(4.3^{-5.8)}\right.\end{array}$ & $\begin{array}{c}4.7^{\mathrm{b}} \\
(2.3-5.2)\end{array}$ \\
\hline
\end{tabular}

\section{Study protocol}

Rats were randomized into three groups of six animals each, a control group, a normal honey group and a mad honey group. Since the average amount of honey used among local people for therapeutic purposes for a 70-kg adult is $4-6$ g/day (1 tea spoon$\mathrm{ful}$ ), each rat was given a mean of $80 \mathrm{mg} / \mathrm{kg}$ per day by the orogastric route throughout the 30 -day study period (10). In order to standardize the amounts given, rats in the normal honey group were also given a mean of $80 \mathrm{mg} / \mathrm{kg}$ per day by the orogastric route throughout the 30-days study period.

On day 18 of the study, rat no. 4 in the normal honey group died and was removed from the study. On the 30th day of the study, rats were anesthetized through intramuscular administration of $50 \mathrm{mg} / \mathrm{kg}$ ketamine and $5 \mathrm{mg} / \mathrm{kg}$ xylazine. Animals were then sacrificed through intracardiac blood collection. Folliclestimulating hormone (FSH), luteinizing hormone ( $\mathrm{LH}$ ), estradiol, progesterone, total testosterone and free testosterone levels were investigated from the blood specimens collected. Serum total testosterone analyses were performed using original kits in a Beckman Coulter UnicelDxI800 immunoassay system. Serum free testosterone analyses were performed using radioimmunoassay on a PC-RIA-MAS device.

\section{Data analysis}

Statistical analysis was performed on SPSS (Statistical Package for Social Sciences for Windows v.22.0; SPSS, Chicago, IL) software. Descriptive statistics for normally distributed data are expressed as mean \pm standard deviation (SD). Descriptive statistics for non-normally distributed data are given as median, minimum and maximum values. Tests of variance were performed to determine whether hormonal values in the mad honey group would differ statistically significantly from those in the normal honey and control groups. Compatibility with normal distribution was investigated using the Shapiro-Wilk test. The independent two sample t test was used to compare normally distributed data (total testosterone, free testosterone, estradiol and progesterone) and the Bonferroni-corrected Mann-Whitney U test to compare nonnormally distributed data (FSH and LH). Significance was set at $\mathrm{p}<0.05$ for all statistical analyses.

\section{Results}

\section{Biochemical analysis}

Total testosterone, free testosterone, estradiol, LH, FSH and progesterone values measured from blood from rats in all groups were measured as $\mathrm{pg} / \mathrm{ml}$. All mean values and standard deviations are shown in tables $1 \mathrm{a}$ and $1 \mathrm{~b}$.

Total testosterone levels in the mad honey group were significantly higher than those in the normal honey and control groups ( $p=0.006$ and $p=0.000$, respectively). No statistically significant difference was observed between blood total testosterone levels in the normal honey and control groups ( $\mathrm{p}=0.1$ ). Box plot of total testosterone is shown in figure 1.

Free testosterone levels in the mad honey group were also significantly higher than those in the normal honey and control groups ( $p=0.023$ and $p=0.010$, respectively). No significant difference was determined between the normal honey and control groups ( $\mathrm{p}$ $=0.94$ ). Box plot of free testosterone is shown in figure 2 .

No significant difference was observed among the groups in terms of mean estradiol, progesterone, FSH or LH values ( $p>0.05$ ).

\section{Discussion}

GTX is a diterpene in terms of chemical structure, referring to a polyhydroxylated cyclic hydrocarbon with a ring structure with no nitrogen content. Mad honey contains 18 GTX isoforms. GTXs 1-4 are described as toxic diterpenoids. GTX 3 is a primary toxic isomer. Despite its toxic effects, mad honey is widely used in traditional Chinese and Indian medicine and in regional treatments in Europe and America, as it is in Turkey. In traditional medicine it is used to treat inflammation, pain, skin diseases, chills and gastrointestinal diseases, and to lower blood pressure $(3,7)$. The phenol compound inside mad honey has been shown to induce high antioxidant activity (11). 


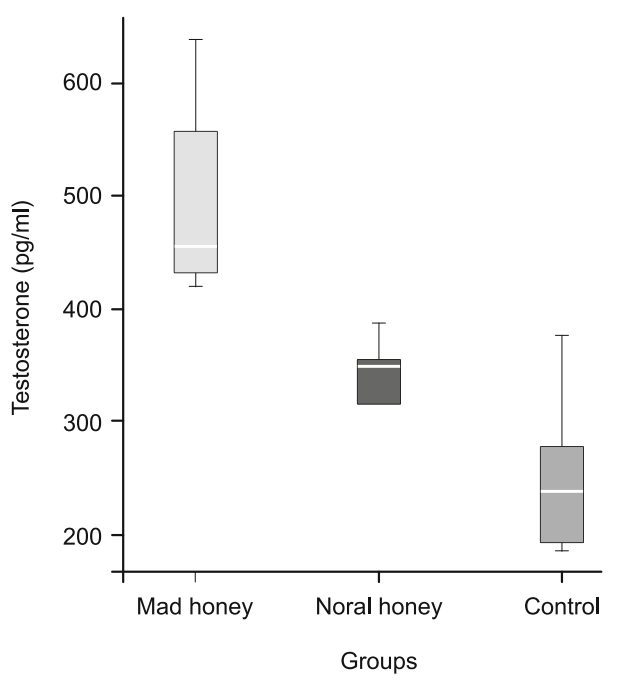

Fig. 1. Boxplot of total testosterone values.

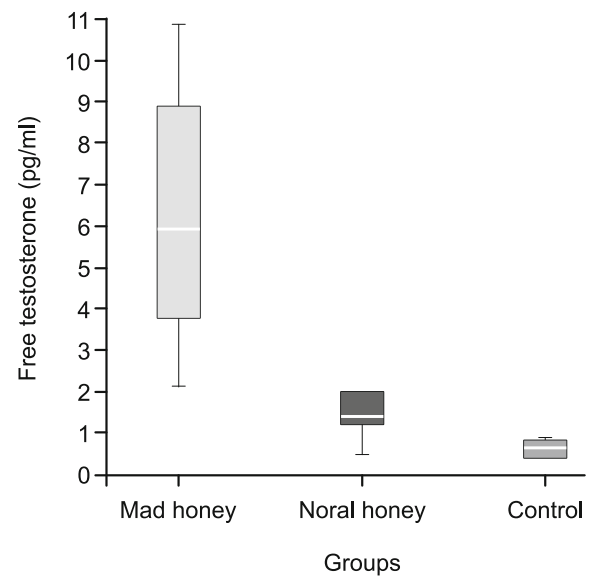

Fig. 2. Boxplot of free testosterone values.

Studies of extracts obtained from Rhododendrons and those involving direct grayanotoxin use have shown that these biological substances possess anti-oxidant, anti-diabetic, cytotoxic, spasmolytic, tyrosinase inhibitory, sedative and acetylcholinesterase inhibitory effects (7). One study reported that Rhododendron ferrugineum shares structural similarities with cannabinoids and that ferruginenes B and C exhibited a tendency to interact with TRPV1 and $\mathrm{CB} 2$ receptor at $20 \mathrm{mM}$ (12).

Lampe wrote in 1988 that "cases of mad honey poisoning should be anticipated everywhere, given potential searches for exotic foods such as natural unprocessed honey realized locally from endemic areas or from imported honey products.” Turkey stands between the continents of Europe and Asia. This means that Turkey is a biological bridge for the migration of plant species (13).

Studies have shown age-dependent cross-sectional declines in total and/or free testosterone levels in men (14). Milligan et al described men aged 58 as the average consumers of sildenafil (Viagra, Pfizer, New York, NY) to treat erectile dysfunction (15).
Interestingly, as described above, the mean age in wide case series of mad honey intoxication published in Turkey ranges between 50 and 55. Male users represent more than $80 \%$ of subjects in these case series. Gündüz et al. reported a mean age of 56 and an $85 \%$ level of male subjects, Demircan et al. a mean age of 55 and an 85.7 \% level of male subjects and Yilmaz et al. a mean age of 51 and an $80.3 \%$ of male subjects $(4,8,9)$. These data show that mad honey is predominantly used among males and subjects over 50 . These findings suggest that a specific age group consumes mad honey to treat erectile dysfunction using traditional methods.

GTXs are classified as toxins that adhere to two sites in the sodium $\left(\mathrm{Na}^{2+}\right)$ channels. They alter the function of the ion channels, resulting in a shift of $\mathrm{Na}^{2+}$ channel activation, resulting in hyperpolarization of transmembrane potentials. This gives rise to deactivation of the $\mathrm{Na} 2+$ channel since this stays open. Repeated, instead of single, long-lasting, depolarizing stimuli, are needed to regulate the $\mathrm{Na}^{2+}$ channels in excitable cells. Another possible explanation of GTX toxicity involves muscarinic receptors, which account for the benefits of atropine in cases of honey intoxication (16). Low doses of GTXs have been reported to lead to dizziness, hypotension, and bradycardia, together with impaired consciousness, syncope, atrioventricular block, and asystole (3).

This study of mad honey observed a significant increase in both total and free testosterone levels compared to the normal honey and control groups. The mechanism involved in this increase in testosterone levels is unclear.

Increases in both total testosterone end free testosterone levels show a real increase of testosterone in mad honey group. If it was increase only of total testosterone levels it would be interpreted as increase in testosterone binding globulin levels. No decrease in FSH and LH levels shows the increase because of induction of hypothalamus/ hypophysis. If mad honeycaused this by effecting the testicles, a decreases in FSH and LH levels would be expected. Furthermore, there is no increase in progesterone levels. Conversely, there is a decrease in progesterone levels which is statistically non-significant. So probably something in mad honey which is not in normal honey induces hypothalamic/hypophysis axis and increases both, free testosterone and total testosterone levels.

This experimental study is an important study because this is the first study investigating the effect of mad honey on sexual performance used in traditional medicine generally for this purpose. Further studies involving larger case series as well as clinical studies are needed to evaluate the effect of mad honey on sexual performance and corroborate these findings.

\section{References}

1. Gunduz A, Turedi S, Oksuz H. The honey, the poison, the weapon. Wilderness Environ Med 2011; 22 (2): 182-184.

2. Gunduz A, Bostan H, Turedi S, Nuhoglu I, Patan T. Wild flowers and mad honey. Wilderness Environ Med 2007; 18 (1): 69-71.

3. Gunduz A, Turedi S, Russell RM, Ayaz FA. Clinical review of grayanotoxin/mad honey poisoning past and present. Clin Toxicol 2008; 46 (5): 437-442. 


\section{7-680}

4. Demircan A, Keles A, Bildik F, Aygencel G, Dogan NO, Gomez HF. Mad honey sex: therapeutic misadventures from an ancient biological weapon. Ann Emerg Med 2009; 54 (6): 824-829.

5. Gunduz A, Eraydin I, Turkmen S et al. Analgesic effects of mad honey (grayanotoxin) in mice models of acute pain and painful diabetic neuropathy. Human Exp Toxicol 2014; 33 (2): 130-135.

6. Türkmen S, Karagöz Ü, Gündüz A, Türedi S, Metehan A, Yildirim $\mathbf{M}$. The dose-dependent effect of grayanotoxin on the cardiovascular system. Turk J Med Sci 2013; 43 (5): 700-705.

7. Popescu R, Kopp B. The genus Rhododendron: an ethnopharmacological and toxicological review. J Ethnopharmacol 2013; 147 (1): 42-62.

8. Gunduz A, Merice ES, Baydin A et al. Does mad honey poisoning require hospital admission? Amer J Emerg Med 2009; 27 (4): 424-427.

9. Yilmaz O, Eser M, Sahiner A, Altintop L, Yesildag O. Hypotension, bradycardia and syncope caused by honey poisoning. Resuscitation 2006; 68 (3): 405-408.

10. Ersunan G. Balin Halk arasinda Kullanimi ve Apikoterapi. In: Gunduz A (Ed). Bal ve Deli Bal. Istanbul: Nobel Tip Kitabevi; 2015, 105-110.
11. Sibel S, Enis YM, Huseyin S, Timucin AA, Duran O. Analysis of grayanatoxin in Rhododendron honey and effect on antioxidant parameters in rats. J Ethnopharmacol 2014; 156: 155-161.

12. Seephonkai P, Popescu R, Zehl M, Krupitza G, Urban E, Kopp B. Ferruginenes A-C from Rhododendron ferrugineum and their cytotoxic evaluation. J Natur Product 2011; 74 (4): 712-717.

13. Lampe KF. Rhododendrons, mountain laurel, and mad honey. JAMA 1988; 259 (13): 2009.

14. Harman SM, Metter EJ, Tobin JD, Pearson J, Blackman MR, Baltimore Longitudinal Study of A. Longitudinal effects of aging on serum total and free testosterone levels in healthy men. Baltimore Longitudinal Study of Aging. J Clin Endocrinol Metab 2001; 86 (2): 724-731.

15. Milligan PA, Marshall SF, Karlsson MO. A population pharmacokinetic analysis of sildenafil citrate in patients with erectile dysfunction. Brit J Clin Pharmacol 2002; 53 (Suppl 1): 45S-52S.

16. Islam MN, Khalil MI, Islam MA, Gan SH. Toxic compounds in honey. J App Toxicol 2014; 34 (7): 733-742.

Received July 13, 2016.

Accepted July 25, 2016 